\title{
Preliminary Evaluation of the HOBO Data Logging Rain Gauge at the Chuzhou Hydrological Experiment Station, China
}

\author{
Zehui Zhou $\mathbb{D}^{1,2}$ Bin Yong $\mathbb{D}^{1,}{ }^{1,2}$ Jiufu Liu, ${ }^{3}$ Aimin Liao, ${ }^{3}$ Niu Wang, ${ }^{3}$ Ziwei Zhu, ${ }^{2}$ Dekai Lu, ${ }^{2}$ \\ Wang Li, ${ }^{2}$ and Jianyun Zhang $^{3}$ \\ ${ }^{1}$ State Key Laboratory of Hydrology-Water Resources and Hydraulic Engineering, Hohai University, Nanjing 210098, China \\ ${ }^{2}$ School of Earth Sciences and Engineering, Hohai University, Nanjing 211100, China \\ ${ }^{3}$ Nanjing Hydraulic Research Institute, Nanjing 210029, China
}

Correspondence should be addressed to Bin Yong; yongbin_hhu@126.com

Received 22 March 2019; Revised 25 July 2019; Accepted 3 October 2019; Published 4 November 2019

Guest Editor: Zia ul-Haq

Copyright (c) 2019 Zehui Zhou et al. This is an open access article distributed under the Creative Commons Attribution License, which permits unrestricted use, distribution, and reproduction in any medium, provided the original work is properly cited.

As a tipping bucket rain gauge, the HOBO Data Logging Rain Gauge RG3-M (RG3-M) has been widely used for the field precipitation observation owing to its superiority of independent power supply by a small portable battery. To quantify the measurement accuracy of the RG3-M gauge, a standard Manual Gauge (MG) and eight other models of tipping bucket rain gauges were installed at the Chuzhou hydrological experiment station of China. In this study, we first compared and investigated the accumulated mounts of 18 rainfall events of two RG3-M gauges benchmarked by the standard MG. Then, five typical rainfall events were chosen to further analyse the observed accuracy of the RG3-M gauge for different rainfall intensities at hourly temporal scale. Finally, the impacts of wind speed and rainfall intensity on the precipitation measurements of the RG3-M gauge were preliminarily explored. Results indicate that the RG3-M gauge measurement generally underestimates rainfall approximately $-4 \%$ against the standard MG observation, but the maximum deviation even reaches $-12.87 \%$. In terms of the hourly rainfall process, the reliable measurement scope of the RG3-M gauge is ranging from 1.5 to $3 \mathrm{~mm} / \mathrm{h}$; however, it should be noted that the underestimation is rather significant at the higher rainfall rates $(>6 \mathrm{~mm} / \mathrm{h})$. Last, it was found that rainfall intensity is a nonnegligible factor for influencing the measurement of the RG3-M gauge. But the windy effect seems to be insignificant in our experiments, which might be attributed to the similar exposure of the compared gauges.

\section{Introduction}

As one of the most important water cycle elements, precipitation is the release of water from the atmosphere to reach the surface of the earth. Measurement of precipitation has a long history, but till now precisely measuring precipitation is still a challenging task due to the high spatiotemporal variability and inhomogeneity of precipitation itself $[1,2]$. Rain gauges can provide point observations of precipitation and are normally recognized as "ground truth" for validating the radar-estimated or satellite-retrieved rainfall [3]. However, in practice, some systematic and random errors, such as the diversity of rain gauge designs, wind-induced gauge undercatch, human operating errors, and the instability of gauge installations, inevitably affect the accuracy of gauge-measured precipitation $[4,5]$.
In previous studies, the World Meteorological Organization (WMO) carried out several intercomparison projects of precipitation measurement, and many efforts have been made to quantify the accuracy of different rain gauges and analyse the uncertainties and biases existing in gaugemeasured precipitation [6-14]. These projects have achieved satisfactory results for the observational performance of the rain gauges they have studied. With the development of the times, it is necessary to study the latest and most practical automatic rain gauge to measure precipitation.

Currently, the Chinese meteorological network operated by the China Meteorological Administration (CMA) consists of over 30,000 automated recording rainfall gauges, most of which are distributed in the eastern and southern regions of China. These automated rain gauges mainly include three types, namely, the tipping bucket rain gauge 
(TBR), the weighing rain gauge, and the siphon rain gauge. Among them, the most popular rain gauge is TBR owing to its simple, durable, highly reliable, and inexpensive design [15-17]. However, the majority of TBRs need an external power supply. As a special model of TBRs, the HOBO Data Logging Rain Gauge RG3-M (RG3-M) is a battery-powered rainfall data collection and recording system, which includes one small lithium battery (3 volt, CR-2032) embedded in its data logger enveloped by waterproof material inside the gauge cylinder. The portable battery could last about 1 year for conventional use. Because of this advantage, RG3-M gauges are particularly well suited to be installed in remote regions for various research studies of meteorology, hydrology, ecology, and agriculture [18-21]. Nevertheless, literature survey suggests a specific investigation for the measuring accuracy of the RG3-M gauge, particularly based on the field experiments, is still lacking.

The focus of this study is entirely experimental. Altogether 10 models of rain gauges installed in the Chuzhou hydrological station, China, were employed to record the rainfall events and raining processes. Here, we collected the observed rainfall data of 18 rainfall events occurred in 2017 to quantify the measurement accuracy of the RG3-M gauge. First, we compared the accumulated rainfall amounts of two tested RG3-M gauges and validate their measuring biases by employing a standard Manual Gauge (MG) as the reference. Next, we furtherly analysed error feature and variation process of different rain gauges with different rainfall intensities at the hourly scale. Finally, we attempted to detect the effects of both wind speed and rainfall intensity on the measurements of the RG3-M gauge during different rainfall events. We believe that our analysis results will be of great interest to both meteorologists and hydrologists who have been or want to be the RG3-M gauge users.

\section{Materials and Methods}

2.1. Observation Site. The experimental observation site is the Chuzhou hydrological experiment station located within the Huashan watershed at the eastern region of Anhui Province, China (Figure 1(a)). The station operated by the Nanjing Hydraulic Research Institute (NHRI) is approximately $87 \mathrm{~km}$ away from the Nanjing city at latitude of $32^{\circ} 17^{\prime} 28.61^{\prime \prime} \mathrm{N}$ and longitude of $118^{\circ} 12^{\prime} 24.31^{\prime \prime} \mathrm{E}$. It has a typical subtropical humid monsoon climate. The main purpose of the station is to monitor the hydrometeorological elements of typical humid climate region and investigate the hydrological mechanism of rainfall-runoff. Our experiments of rainfall observations were performed at the Hydrometeorological Observation Field (Figure 1(b)), which is just situated in the centre of the station. In 2012, an automatic weather station system and a near-surface meteorological gradient observation system were installed in the field to obtain the conventional meteorology elements, mainly including rainfall, relative humidity, total radiation, soil temperature, and atmospheric pressure, and the wind speed, air temperature, and relative humidity at different heights (2, $4,6,8$, and 10 meters).
2.2. Rain Gauges. To comprehensively intercompare the measuring features of different rain gauges, we installed a manual gauge (MG) and nine models of TBRs at the Hydrometeorological Observation Field in 2016, including the RG3-M, TR-525, TR-525M, JDZ01, JDZ02, JDZ05, JDZ10, TJ01, and TJ05. Figure 1(c) shows the spatial positions of all rain gauges in the field. The distance between two adjacent rain gauges is controlled within 1-2 $\mathrm{m}$. According to the Chinese national standard, all gauges were installed in the field with $70 \mathrm{~cm}$ length from the TBR top to the ground surface. During the installation, all the connection cables between the gauge and the logger are enclosed in a weatherproof box to avoid direct exposure to the air. The instrument parameters of ten models of rain gauges are summarized in Table 1.

First, the MG was installed at the field for benchmarking the total rainfall amounts measured by all the TBRs. Currently, the MG-measured rainfall amounts can be obtained by two ways, i.e., the weighting method and the horizontal visual method with a measuring cylinder. There is small difference between these two experimental methods. Hence, here we selected the latter owing to its simple operation (Figure 2(d)).

As for the three TBRs (RG3-M, TR-525, and TR-525M) made in USA, one can note that they have different resolution $(0.2 \mathrm{~mm}, 0.254 \mathrm{~mm}$, and $0.1 \mathrm{~mm})$ and barrel diameter (152.4 mm, $163 \mathrm{~mm}$, and $245 \mathrm{~mm}$ ). The data logger of RG3$\mathrm{M}$, whose power source comes from a small lithium battery, can record the time of each tip and the instantaneous temperature (Figure 2(c)). The TR-525 gauge has been tested and used in the Ohio's Upper Big Walnut Creek Watershed [15]. The experimental results showed that the TR-525 gauge has a larger deviation compared to other gauges.

Additionally, the series of JDZ and TJ gauges have been widely applied in China for the liquid precipitation observations. In our study, there are four types of JDZ gauges, which represent four different resolutions, i.e., JDZ01 $(0.1 \mathrm{~mm})$, JDZ02 $(0.2 \mathrm{~mm})$, JDZ05 $(0.5 \mathrm{~mm})$, and JDZ10 $(1.0 \mathrm{~mm})$, respectively. Differing from other TBRs, the TJ gauges do not have the filter screen which can screen out various fragments such as leaves and branches. In the experimental field, there are two models of TJ gauges, i.e., TJ01 and TJ05 with resolutions of $0.1 \mathrm{~mm}$ and $0.5 \mathrm{~mm}$, respectively. Specifically, the barrel diameter of all rainfall gauges made in China is the same $200 \mathrm{~mm}$. Note that the resolution $(0.2 \mathrm{~mm})$ of the studied RG3-M is the same as that of JDZ02.

2.3. Laboratory Calibration. Based on the reference of $\mathrm{GB} / \mathrm{T}$ 11832-2002 "tipping bucket rain gauge" [22] and the WMO laboratory calibration standard, all the experimental TBRs were first calibrated individually in the laboratory before installation in the field. The calibration process mainly consists of two steps. For the first step, we performed the volumetric calibration for rain gauges. By pouring $10 \mathrm{~mm}$ water into the tested gauge each time, we recorded the counting number of the tipping bucket and then carefully adjusted the correction screw under the gauge base. This 


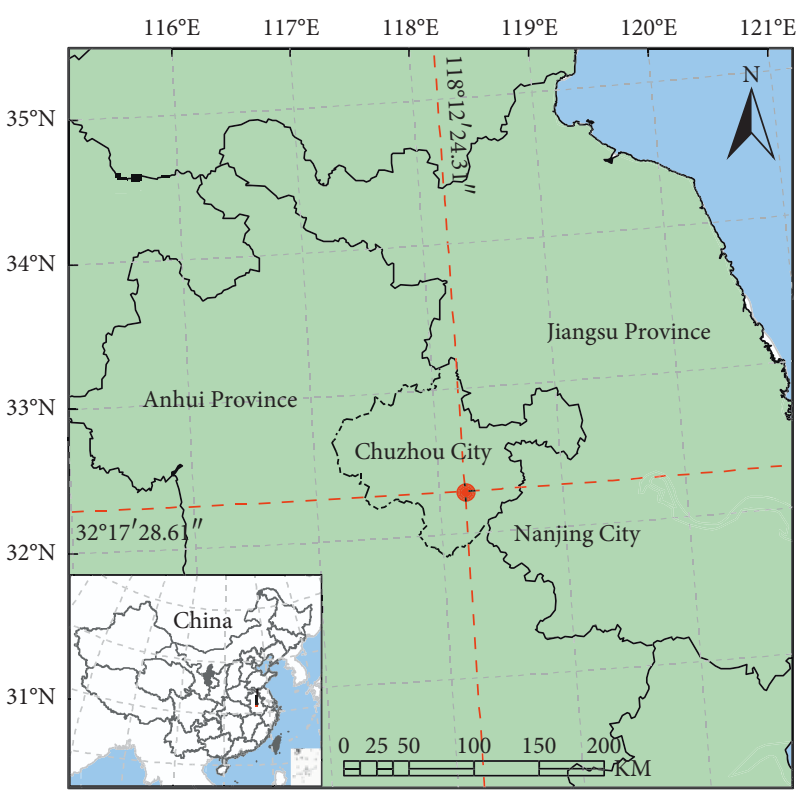

(a)

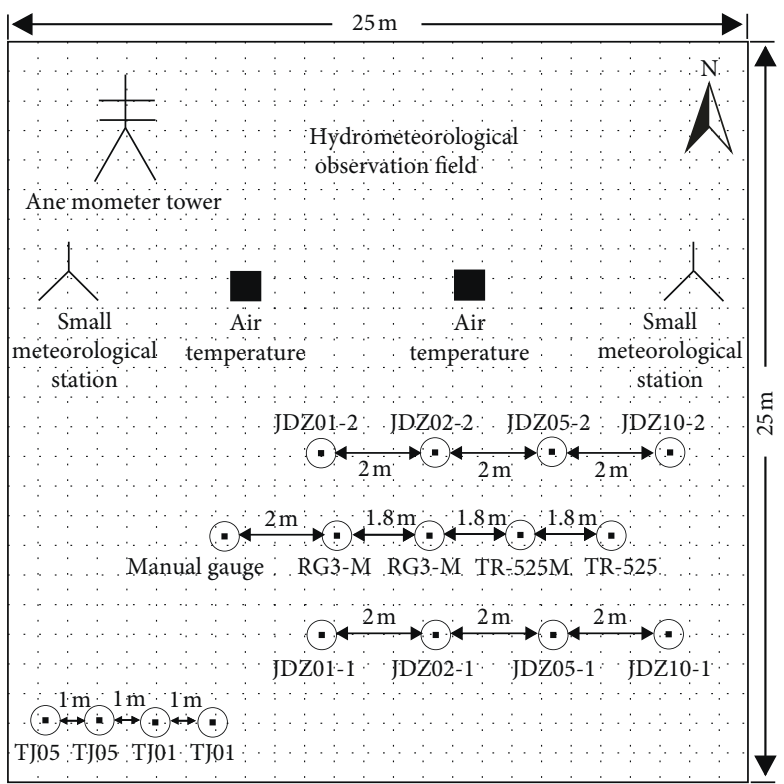

(b)

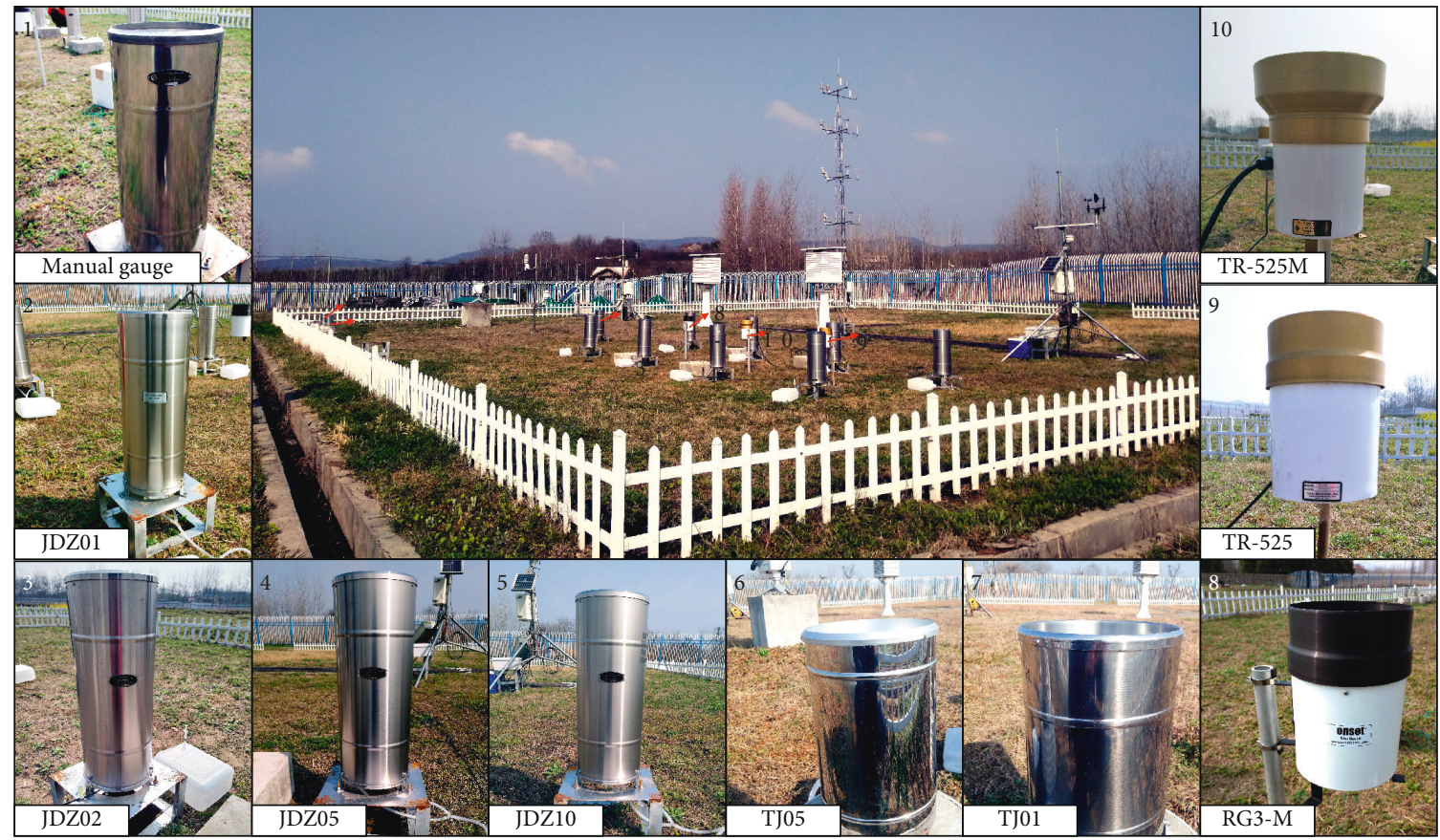

(c)

Figure 1: (a) Field view of the Chuzhou hydrological experiment station, (b) distribution of 10 models rain gauges, and (c) the site of hydrometeorological observation field.

process was repeated several times for each gauge till that the tipping bucket reached the required resolution. Second, we carried out the dynamic calibration for each rain gauge. The dynamic calibration used an automatic calibration device developed by the Nanjing Hydraulic Research Institute (NHRI) [23], which can produce a series of water flows with different speeding rates to simulate different rainfall intensities (Figure 3). This calibration device can also be applied in the field, especially for the periodical test and adjustment for the installed TBRs (Figures 2(a)-2(c)).
The purpose of dynamic calibration is to eliminate systematic error as far as possible. Apart from the systematic errors, rain gauges also suffer from random errors. These errors should be kept in mind in comparison with the gauge rainfall.

2.4. Data Collection. At the experiment field, the amount of liquid precipitation obtained from the MG was accurately measured after each rainfall event. All data from TBRs but 
TABLE 1: Instrumental information at the Chuzhou hydrological experiment station.

\begin{tabular}{|c|c|c|c|c|c|c|c|}
\hline $\begin{array}{l}\text { Model of } \\
\text { gauge }\end{array}$ & Origin & $\begin{array}{l}\text { Resolution } \\
(\mathrm{mm})\end{array}$ & $\begin{array}{l}\text { Splash out } \\
\text { protection } \\
(\mathrm{cm})\end{array}$ & Rainfall rate & $\begin{array}{l}\text { Diameter } \\
(\mathrm{mm})\end{array}$ & $\begin{array}{c}\text { Operating } \\
\text { temperature range } \\
\left({ }^{\circ} \mathrm{C}\right)\end{array}$ & $\begin{array}{c}\text { Calibration } \\
\text { accuracy (\%) }\end{array}$ \\
\hline Manual gauge & $\begin{array}{l}\text { Jiangsu, } \\
\text { China }\end{array}$ & - & - & - & 200 & - & - \\
\hline $\begin{array}{l}\text { HOBO RG3- } \\
\mathrm{M}\end{array}$ & USA & 0.2 & 5 & $\leq 2.12 \mathrm{~mm} / \mathrm{min}$ & 152.4 & $0 \sim+50$ & $\begin{array}{l} \pm 1.0 \text { (up to } 2 \mathrm{~cm} \\
\text { per hour) }\end{array}$ \\
\hline TR-525 & USA & 0.254 & 5 & $\leq 11.67 \mathrm{~mm} / \mathrm{h}$ & 163 & $0 \sim+50$ & $\begin{array}{l} \pm 1.0 \text { (up to } 5 \mathrm{~cm} \\
\text { per hour) }\end{array}$ \\
\hline TR-525M & USA & 0.1 & 5 & $\leq 11.67 \mathrm{~mm} / \mathrm{h}$ & 245 & $0 \sim+50$ & $\begin{array}{l} \pm 1.0 \text { (up to } 5 \mathrm{~cm} \\
\text { per hour) }\end{array}$ \\
\hline JDZ01 & $\begin{array}{l}\text { Jiangsu, } \\
\text { China }\end{array}$ & 0.1 & 14 & $\leq 4 \mathrm{~mm} / \mathrm{min}$ & 200 & $-10 \sim+55$ & $\leq 4.0$ \\
\hline JDZ02 & $\begin{array}{l}\text { Jiangsu, } \\
\text { China }\end{array}$ & 0.2 & 14 & $\leq 4 \mathrm{~mm} / \mathrm{min}$ & 200 & $-10 \sim+55$ & $\leq 4.0$ \\
\hline JDZ05 & $\begin{array}{l}\text { Jiangsu, } \\
\text { China }\end{array}$ & 0.5 & 14 & $\leq 4 \mathrm{~mm} / \mathrm{min}$ & 200 & $-10 \sim+55$ & $\leq 4.0$ \\
\hline JDZ10 & $\begin{array}{l}\text { Jiangsu, } \\
\text { China }\end{array}$ & 1.0 & 14 & $\leq 4 \mathrm{~mm} / \mathrm{min}$ & 200 & $-10 \sim+55$ & $\leq 4.0$ \\
\hline TJ05 & $\begin{array}{l}\text { Tianjin, } \\
\text { China }\end{array}$ & 0.5 & 20 & $\leq 5 \mathrm{~mm} / \mathrm{min}$ & 200 & $-10 \sim+50$ & $\leq 5.0$ \\
\hline TJ01 & $\begin{array}{l}\text { Tianjin, } \\
\text { China }\end{array}$ & 0.1 & 20 & $\leq 5 \mathrm{~mm} / \mathrm{min}$ & 200 & $-10 \sim+50$ & $\leq 5.0$ \\
\hline
\end{tabular}
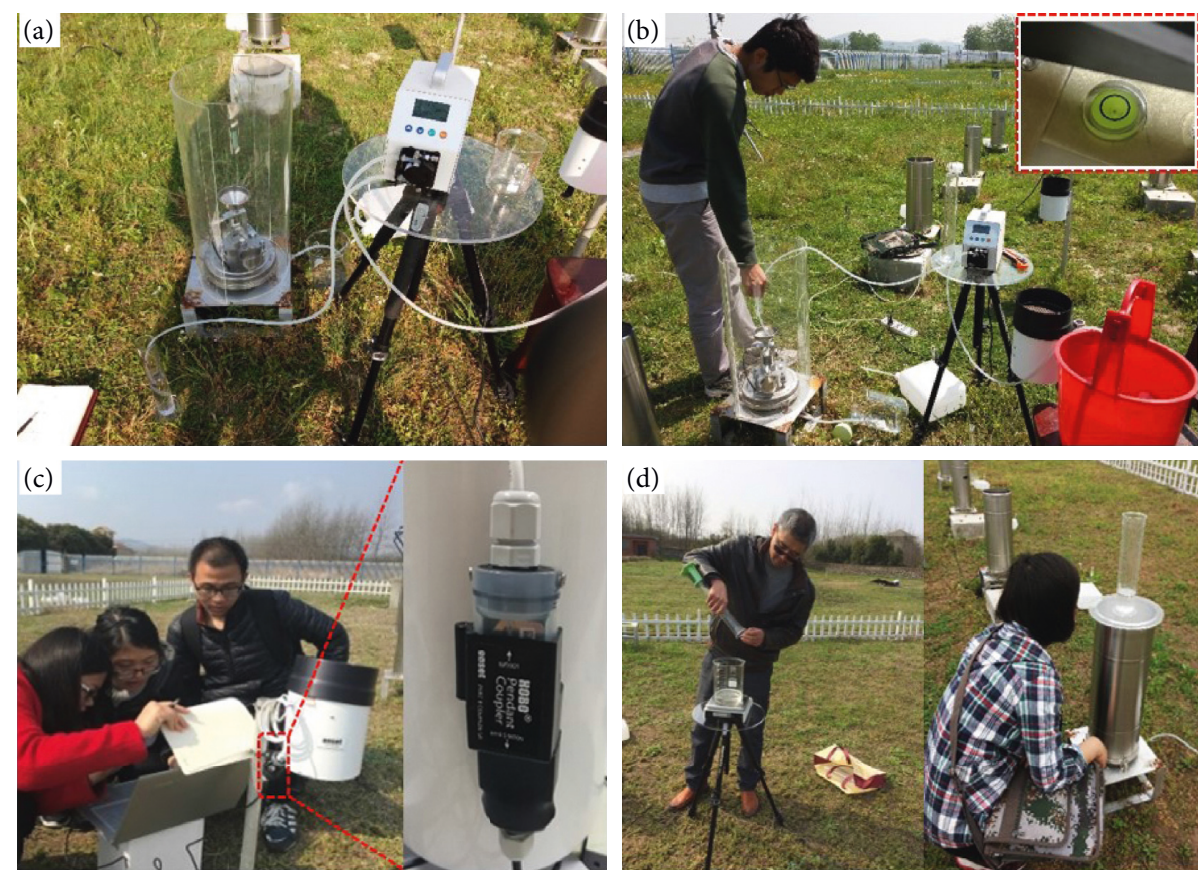

Figure 2: (a) Peristaltic pump used for calibration. (b) The calibration of tipping bucket rain gauge. (c) Obtaining the data from RG3-M (left), the data logger (right). (d) Comparison of precipitation measurement for the manual gauge: weighting method (left) and horizontal visual method (right).

for RG3-M record through a data acquisition system in time step of one minute. The data logger of the RG3-M gauge can instantaneously record both rainfall amount and temperature when the gauge collects $0.2 \mathrm{~mm}$ of rainfall to trigger the tipping bucket flipping once. By dynamic calibration testing, we found that the mechanical biases of RG3-M gauges have been corrected before they leave the factory. The wind speed at the height of $2 \mathrm{~m}$ observed by the automatic weather station system was made available at $10 \mathrm{~min}$ resolution. All meteorological data were performed by the data quality control in this study.

\section{Methods}

In this study, we adopt the approaches proposed by Duchon and Essenberg [3] and Tokay et al. [24] to comprehensively evaluate the performance of the RG3-M gauge from three perspectives. First, we validated the observation accuracy of 


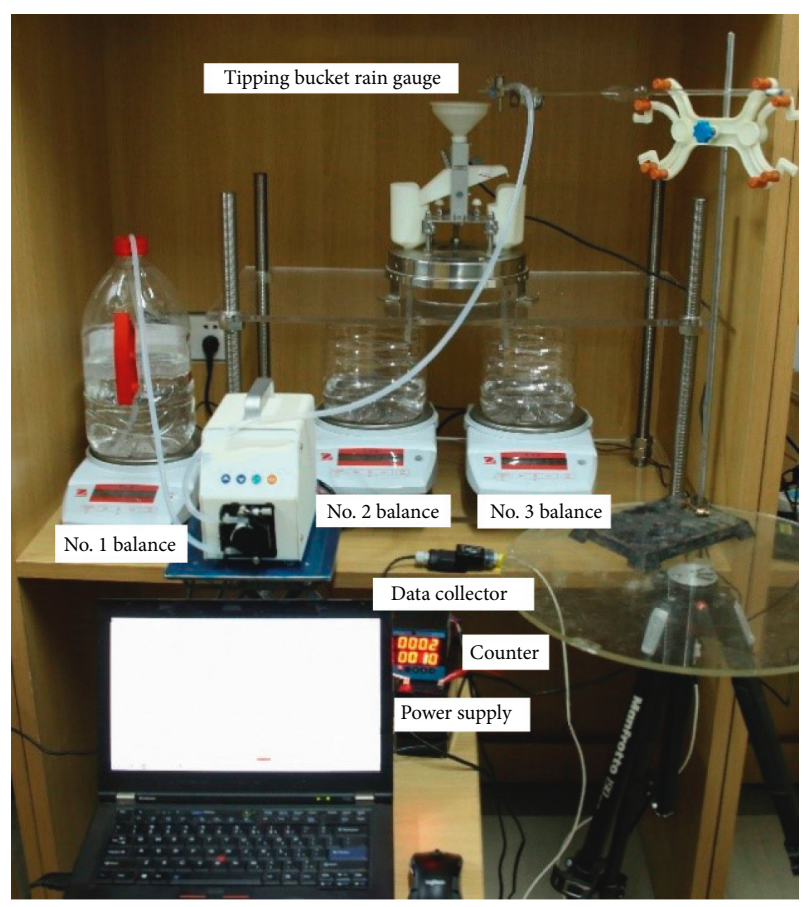

Figure 3: Calibration system.

RG3-M for rainfall events benchmarked by the MG gauge. Two statistical indices, namely, the Relative Bias (BIAS) and Relative Root Mean Squared Error (RRMSE), are used to calculate the error of RG3-M against the MG gauge. The BIAS measures the systematic errors, whereas the RRMSE is amplified by both systematic and nonsystematic errors. The formulas for the two statistics are

$$
\begin{aligned}
\text { BIAS } & =\frac{T_{\mathrm{g}}-T_{\mathrm{m}}}{T_{\mathrm{m}}} \times 100 \%, \\
\text { RRMSE } & =\frac{\sqrt{(1 / n) \sum_{i=1}^{n}\left(T_{\mathrm{g}}-T_{\mathrm{m}}\right)^{2}}}{(1 / n) \sum_{i=1}^{n} T_{\mathrm{m}}},
\end{aligned}
$$

where $n$ represents the sample size at each rain intensity range, and $T_{\mathrm{g}}$ and $T_{\mathrm{m}}$ represent the total rainfall of each event recorded by the gauge and MG, respectively. Second, the validation of rainfall events cannot completely reflect the observation ability of a rain gauge because the dynamic change of precipitation has also obvious distinctions at shorter time scales rather than at event scale [5]. Considering that it is impossible to get referenced rainfall at short time scales by MG, here we will select a best TBR with the highest observation accuracy to test the rainfall measurements of RG3-M at hourly scale. Finally, we analysed the impact of both wind speed and rainfall intensity on RG3-M on the basis of the wind speed and the rainfall intensity corresponding to the recording step of hourly rain observations.

\section{Results and Discussion}

4.1. Rainfall Events. The observed rainfall and meteorological data from March to September in 2017 are used in our study. The rainfall data can provide 18 complete rainfall events. Figure 4 demonstrates the comparison results between two RG3-M gauges and MG. As can be seen from Figure 4(a), the RG3-M gauges generally underestimate the rainfall amounts for almost all the events compared to the referenced MG (Figure 4(a)). In terms of the average precipitation intensity for each event, the BIAS of RG3-M ranges from $-12.87 \%$ to $3.92 \%$ (Figure $4(\mathrm{~b})$ ). Thus, the average BIAS of RG3-M is calculated as $-3.96 \%$, which mainly contributed from light and moderate rain events. During the raining process, we found that the screen strainer of RG3-M is easier to form a kind of thin liquid sheet, which easily rebounds some raindrops out of the gauge especially for larger rainfall. Additionally, the diameter of RG3-M (152.4 mm) is smaller than that of the MG $(200 \mathrm{~mm})$ and other TBRs (see Table 1). In particular, we also note that the length from barrel top to screen strainer of RG3-M is much shallower than that of other gauges. This is likely to be the major reason for the underestimation of RG3-M observation. According to different rain intensity ranges, next we categorized the 18 rainfall events into 4 classes, i.e., 0$0.5 \mathrm{~mm} / \mathrm{h}, 0.5-1.5 \mathrm{~mm} / \mathrm{h}, 1.5-3 \mathrm{~mm} / \mathrm{h}$, and $\geq 3 \mathrm{~mm} / \mathrm{h}$, respectively. With regard to BIAS, the RG3-M gauges have rather good agreement (average bias $=1.79 \%$ ) with $\mathrm{MG}$ at the range of $1.5-3.0 \mathrm{~mm} / \mathrm{h}$, while they exhibit an obvious underestimation $(<-4 \%)$ at other intensity ranges. As for RRMSE, the error value $(3.05 \%)$ is closer to zero for the range of $1.5-3.0 \mathrm{~mm} / \mathrm{h}$ than other ranges, which is consistent with that of BIAS. Our experimental results indicate that the best range of rain intensity for RG3-M is $1.5-3.0 \mathrm{~mm} / \mathrm{h}$ (Figure 4(c)).

Since the MG can only record the total precipitation for every raining event, it could not reflect the variation process of rainfall at short time scale. It is necessary to select an accurate tipping bucket gauge for validating the hourly rainfall of the RG3-M gauge. Comparison results of other TBRs against MG are provided in Table 2. In general, the JDZ gauges underestimate the rainfall amounts and the other gauges overestimate the rainfall amounts. It can be seen that the TR-525 gauge shows a larger deviation (average bias up to $20 \%$ ), which is similar to the conclusion in Shedekar et al. [25]. The average bias of TJ05 gauge is $3.02 \%$, which is another positive deviation gauge besides TR-525 gauge, but its value is smaller than TR-525. As for the JDZ gauges, the overall underestimation is greatest in the case of JDZ01 gauge (average bias $=-18.07 \%$ ), followed by JDZ02 gauge (average bias $=-4.47 \%$ ) and JDZ10 gauge (average bias $=-4.14 \%$ ), and the best is JDZ05 gauge (average bias $=-1.51 \%)$. Moreover, the performance of the two JDZ05 gauges is rather stable since they record almost the same amount of total rainfall. In addition, JDZ05 matched with the MG measurements rather well and is always equivalent to the average values of all the TBRs for three typical rainfall events with different magnitudes (Figure 5). Therefore, in this study, we selected the JDZ05 gauge as the benchmark for detecting the varying errors of RG3-M at the hourly scale. 


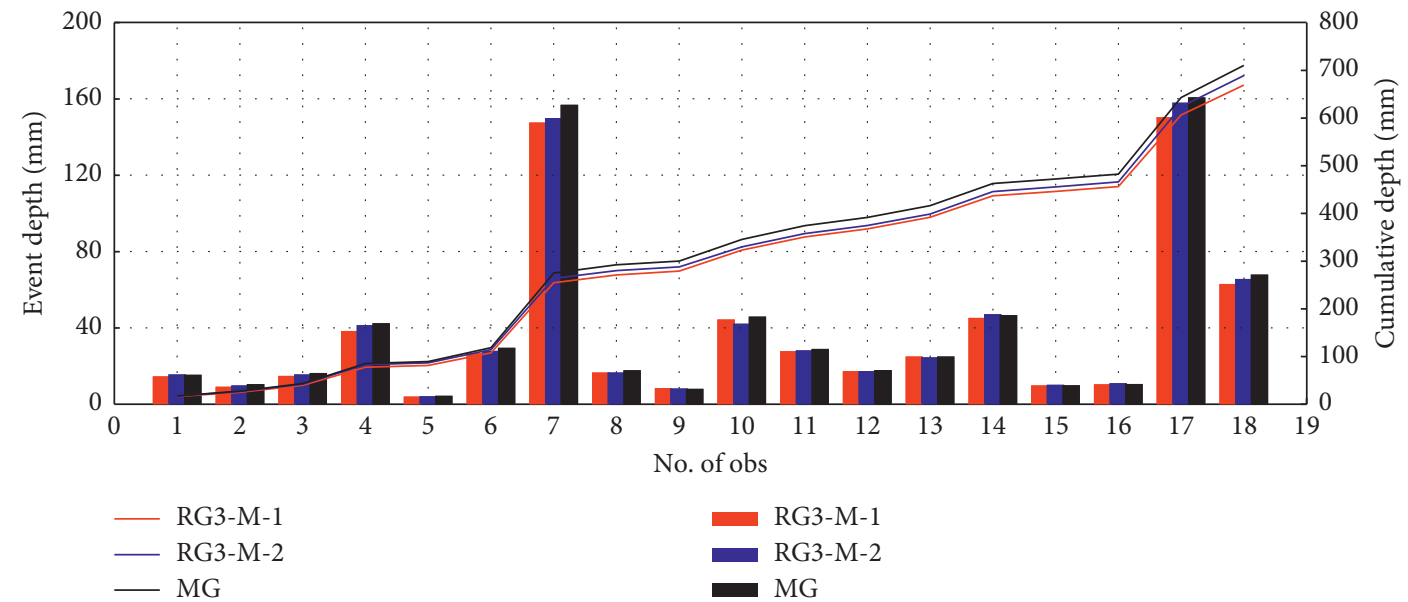

(a)
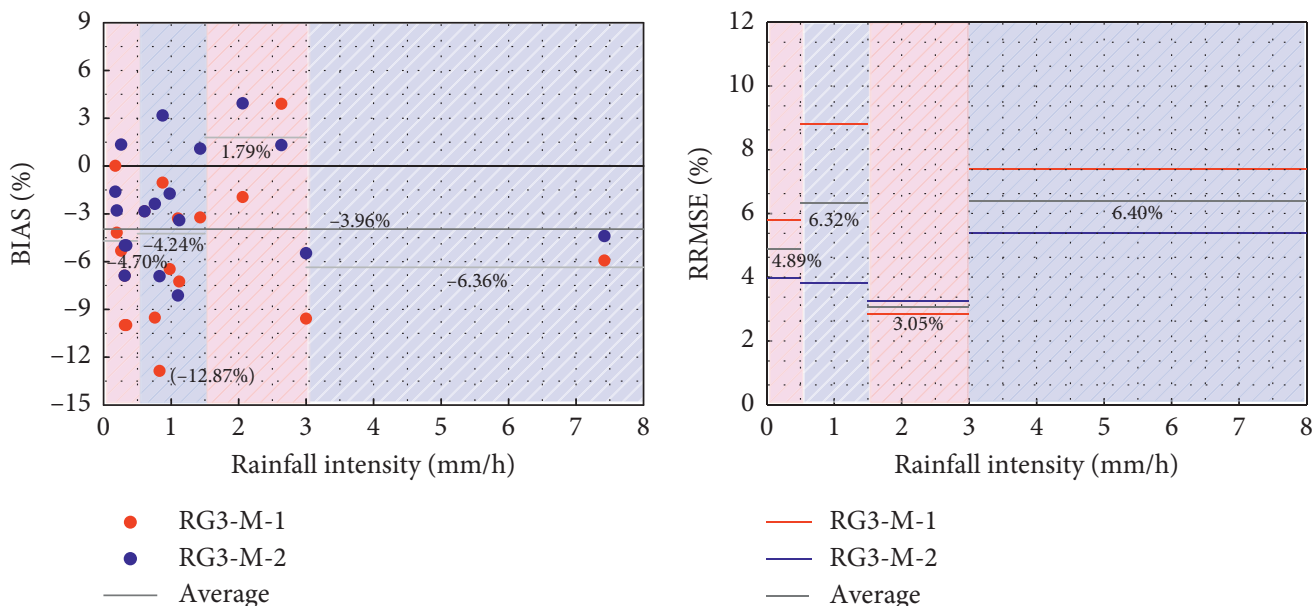

(b)

(c)

Figure 4: (a) Rainfall data measured by RG3-M gauges at the hydrometeorological observation field during 18 rainfall events compared to data recorded at the adjacent MG (bars represent event totals, and lines represent cumulative rainfall depth). (b) The relationship between BIAS and rainfall intensity (rainfall total $\div$ even duration) using event total amounts. (c) The distribution of RRMSEs at four rain intensity ranges.

TABLE 2: Total precipitation ( $\mathrm{mm}$ ) and BIAS (\%) for 11 rain gauges against the manual gauge in five rainfall events at hydrometeorological observation field.

\begin{tabular}{|c|c|c|c|c|c|c|c|c|c|c|c|c|}
\hline & \multirow{2}{*}{ Manual gauge $(\mathrm{mm})$} & \multicolumn{2}{|c|}{ JDZ (0.1mm) } & \multicolumn{2}{|c|}{ JDZ (0.2 mm) } & \multicolumn{2}{|c|}{$\mathrm{JDZ}(0.5 \mathrm{~mm})$} & \multicolumn{2}{|c|}{$\mathrm{JDZ}(1.0 \mathrm{~mm})$} & \multicolumn{2}{|c|}{$\mathrm{TJ}(0.5 \mathrm{~mm})$} & \multirow{2}{*}{ TR-525 $(0.254 \mathrm{~mm})$} \\
\hline & & JDZ01-1 & JDZ01-2 & JDZ02-1 & JDZ02-2 & JDZ05-1 & JDZ05-2 & JDZ10-1 & JDZ10-2 & TJ05-1 & TJ05-2 & \\
\hline \multicolumn{13}{|c|}{2017 03/19 05:01-03/20 08:00 } \\
\hline Total (mm) & 8 & 6.4 & 6 & 7.4 & 7 & 7 & 7 & 8 & 6 & 8.5 & 7.5 & 9.144 \\
\hline BIAS (\%) & 0 & -20.00 & -25.00 & -7.50 & -12.50 & -12.50 & -12.50 & 0 & -25.00 & 6.25 & -6.25 & 14.30 \\
\hline \multicolumn{13}{|c|}{2017 04/04 17:01-04/06 16:00 } \\
\hline Total (mm) & 16 & 13.8 & 13.3 & 16 & 15.4 & 16 & 16.5 & 17 & 16 & 16.5 & 16.5 & 19.812 \\
\hline BIAS (\%) & 0 & -13.75 & -16.88 & 0 & -3.75 & 0 & 3.13 & 6.25 & 0 & 3.13 & 3.13 & 23.83 \\
\hline \multicolumn{13}{|c|}{2017 04/08 19:01-04/11 01:00 } \\
\hline Total (mm) & 42 & 30.4 & 34.9 & 42.4 & 41.4 & 43 & 43 & 45 & 42 & 42.5 & 44 & 53.086 \\
\hline BIAS (\%) & 0 & -27.62 & -16.9 & 0.95 & -1.43 & 2.38 & 2.38 & 7.14 & 0 & 1.19 & 4.76 & 26.40 \\
\hline \multicolumn{13}{|c|}{2017 04/16 18:01-04/17 05:00 } \\
\hline Total (mm) & 4 & 3.3 & 3.1 & 3.8 & 3.6 & 4 & 4 & 4 & 3 & 4 & 4.5 & 4.826 \\
\hline BIAS (\%) & 0 & -17.5 & -22.5 & -5 & -10 & 0 & 0 & 0 & -25 & 0 & 12.5 & 20.65 \\
\hline \multicolumn{13}{|c|}{2017 05/03 23:01-05/04 08:00 } \\
\hline Total (mm) & 29.2 & 28 & 24.4 & 28.8 & 28 & 29.5 & 29.5 & 30 & 27 & 30 & 30 & 36.322 \\
\hline BIAS (\%) & 0 & -4.11 & -16.44 & -1.37 & -4.11 & 1.03 & 1.03 & 2.74 & -7.53 & 2.74 & 2.74 & 24.39 \\
\hline$M B(\%)$ & 0 & \multicolumn{2}{|c|}{-18.07} & \multicolumn{2}{|c|}{-4.47} & \multicolumn{2}{|c|}{-1.51} & \multicolumn{2}{|c|}{-4.14} & \multicolumn{2}{|c|}{3.02} & 21.92 \\
\hline
\end{tabular}

Notes: MB = mean BIAS of same model gauges; JDZ01-1 = No.1 JDZ01 rain gauge; JDZ01-2 = No.2 JDZ01 rain gauge; other models of rain gauge are the same as above. 

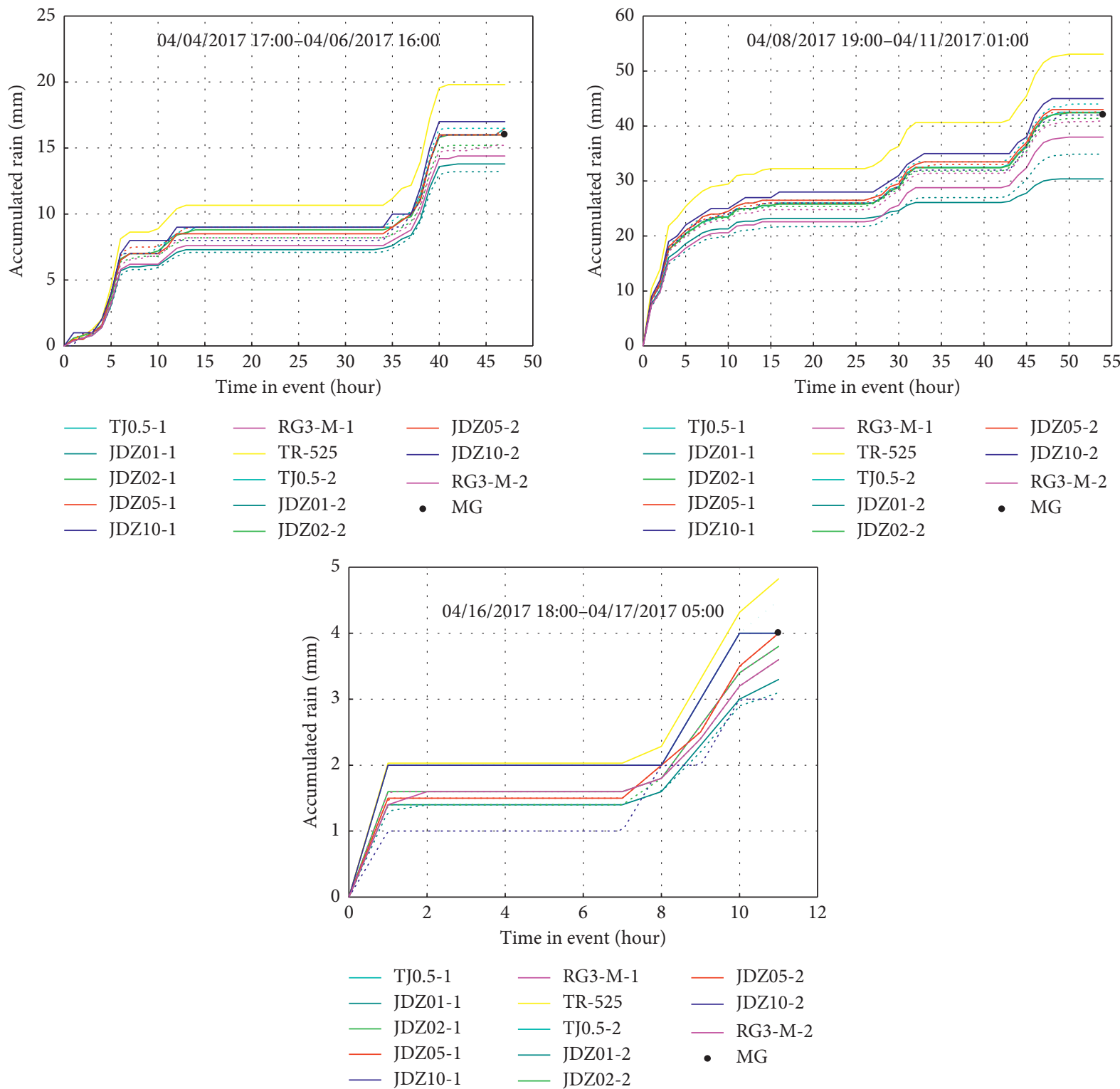

FIgURE 5: Cumulative rainfall measured by 13 rain gauges for three storms on 4 April 2017, 8 April 2017, and 16 April, 2017 recorded at the Hydrometeorological Observation Field, respectively (dot indicates the total depth of rainfall recorded by the manual gauge).

4.2. Hourly Rainfall. Considering that the difference of resolution between RG3-M and JDZ05 might cause errors at a short time step, we adopt the average hourly rainfall of two gauges with the same model in our comparison. Figure 6 shows the comparison of average hourly rainfall observation obtained from the RG3-M gauges against that of the JDZ05 gauges. Altogether, 67 hourly rainfall events were involved in the analysis. In this scattergram, a summary of the comparison between the two variables is shown in the upper left. The purpose of these summaries is to obtain a sense of the actual magnitude of differences in contrast to the results from linear regression. The solid line is the 1:1 line, and the dashed line is the least squares simple linear regression of the RG3-M gauge onto the JDZ05 gauge. The regression equation is given in the lower right quadrant of the figure.
The hourly precipitation of RG3-M and JDZ05 exhibits an evident linear distribution with $R^{2}$ of 0.993 (Figure 6). However, the scatter points slightly fluctuate around the fit line under the light rain intensity $(0-2 \mathrm{~mm} / \mathrm{h})$. This could be attributed to the different resolution of the two gauges (0.2 $\mathrm{mm}$ for RG3-M but $0.5 \mathrm{~mm}$ for JDZ05), which also explained the relatively larger negative bias of RG3-M against JDZ05 (-11.02\%). These two models of gauges show a good agreement at the range of moderate rain $(2-3 \mathrm{~mm} / \mathrm{h})$, which is consistent with the result in Figure 4. In addition, one can see that the underestimation of RG3-M is gradually increasing with the increase of rain intensity especially for the range of exceeding $3 \mathrm{~mm} / \mathrm{h}$. It is because the smaller tipping bucket of the RG3-M gauge could not flip quickly when the rain intensity increases beyond the threshold, which is consistent with the limitations of tipping bucket 


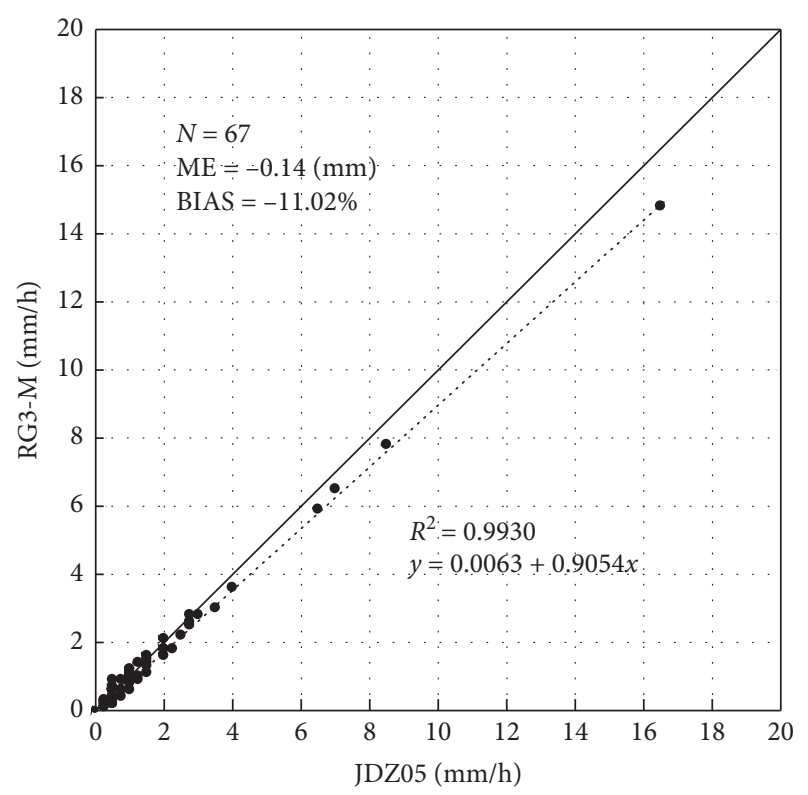

FIGURE 6: Comparison of average hourly rainfall of the RG3-M gauge and the JDZ05 gauge at the hydrometeorological observation field.

rain gauges described by Molini et al. [26]. In a word, The RG3-M gauge rainfall event totals are, on the average, $-11.02 \%$ smaller than those of the JDZ05 gauge, and the average absolute difference is $0.14 \mathrm{~mm}$, which mainly results from the difference in moderate and large rain intensities.

\subsection{Impact of Wind Speed and Rainfall Intensity on RG3-M} Measurements. To further understand the performance of RG3-M in the field experiments, next we examined the hourly difference between RG3-M and JDZ05 considering both wind speed at $2 \mathrm{~m}$ height and rainfall intensity. The analysis in this section aims to identify the possible dominant factor influencing the observed accuracy of rain gauges.

Figures $7(a)-7$ (c) display scatterplots showing the differences between the two RG3-Ms as a function of wind speed, rainfall intensity, and both factors, respectively. The figure plots show that the range of the difference varies from $0 \mathrm{~mm}$ to $0.8 \mathrm{~mm}$ under different conditions of wind speed and rainfall intensity. Generally, the hourly measurements of the two gauges with the same model of RG3-M are almost equal each other. Their difference is less than $0.2 \mathrm{~mm}$ (only one tip of RG3-M) per hour, which most likely is due to the time interval and random errors. The consistent performance of the different RG3-M gauges also further verified the reliability of the volumetric calibration procedure used in our experiments. On the other hand, the stability of RG3-M gauge seems to be hardly affected by wind speed. However, Figure 7(b) suggests that the difference between these two RG3-M gauges increased obviously with the increase of rainfall intensity. Even for lower wind speeds less than $2 \mathrm{~m} / \mathrm{s}$, there still exist some rainy events with higher differences due to different rainfall intensity. Further data analysis confirmed that these points are mainly associated with high rain intensity despite low wind speed.
Similarly, we also plotted the difference between RG3-M and JDZ05 at different wind speeds $(2 \mathrm{~m}$ height) and different rain intensities in Figures 7(d)-7(f). With the increase of wind speed, the difference does not exhibit any apparent tendency (Figure $7(\mathrm{~d})$ ). However, the difference between the two models of rain gauges shows a clear upward trend with the increasing rainfall intensity (Figure $7(\mathrm{e})$ ). This result remains consistent with that in Figure $7(\mathrm{~d})-7(\mathrm{f})$.

To further reveal the impact of wind speed and rainfall intensity on rain gauges, we combined these two crucial factors together to analyse the variations of observation difference (see Figure 7(c) and 7(f)). It is apparent that the RG3-M gauge generally demonstrates a relatively poor performance at high rainfall intensity, while the wind speed does not show a significant effect on observation difference between different rain gauges. As for the wind impacts on rain gauges, there still exist disagreements in the prior studies. For example, analysing some experimental observations in the field, Yang et al. [27] considered that the impact of wind speed on the measurements of rain gauges can be negligible. But some other researchers found that the wind could induce undercatch of rain gauges [28, 29]. Our evaluation result cannot support this viewpoint probably due to the relatively small wind speed (less than $5 \mathrm{~m} / \mathrm{s}$ ) observed during the experiments. Such weak wind could not produce significant impacts on the measurements of liquid precipitation in the experimental field site.

Last but not least, we have to admit that the JDZ05 gauge used as a benchmark in this study was exposed to wind in the same way as the tested RG3-M gauge. This is likely to be the cause that led to the little difference between RG3-M and JDZ05. Therefore, an effective windshield device needs to be applied for eliminating the wind impact in the future experiments. In addition, Duchon and Essenberg [3] mentioned that the spatiotemporal distribution of raindrop size played an important role in the magnitude of undercatch. Through a numerical simulation, Nešpor and Sevruk [30] found that larger fraction of smaller raindrops and higher wind speeds could cause greater undercatch for rain events. To better explore the effects of wind and rainfall intensity on the accuracy of the RG3-M gauge, we are installing two raindrop spectrometers at the experimental site. It is anticipated that the impact of several crucial factors on measurements of rain gauges can be revealed better, especially with different wind speed and raindrop size.

\section{Conclusions}

In this study, measuring accuracy of the portable RG3-M gauge widely used in remote regions was comprehensively investigated by comparing with other 9 models of TRBs at the Chuzhou hydrological experiment station in China. Benchmarked by the standard manual gauge, the rainfall observation of the RG3-M gauge exhibits a clear underestimation with the average bias of $-3.96 \%$, ranging from $-12.87 \%$ to $3.92 \%$. The underestimation of RG3-M might be attributed to some design flaws itself, such as smaller screen mesh and shallow screen strainer (see Supplementary Materials (available here)), which can cause some raindrops 


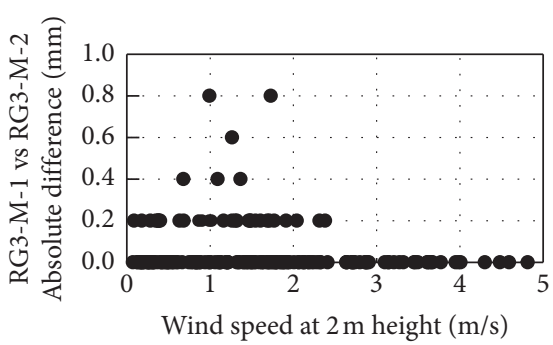

(a)

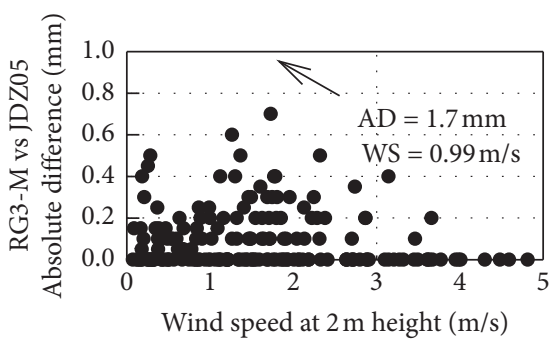

(d)

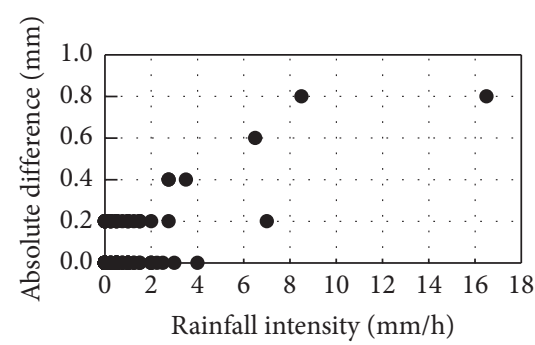

(b)

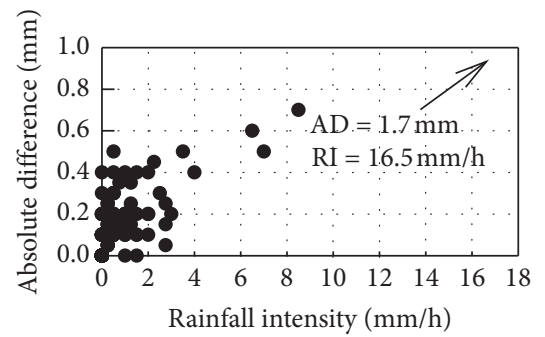

(e)

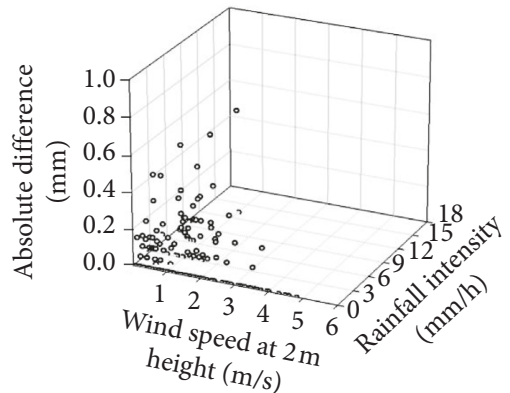

(c)

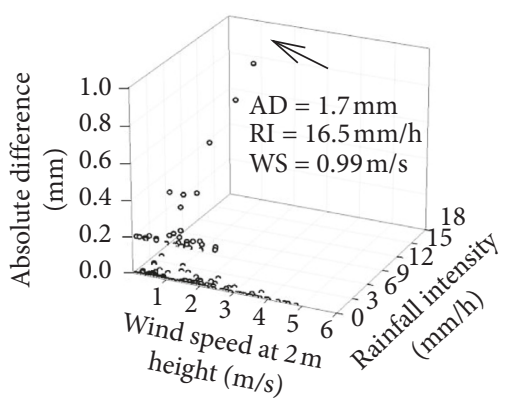

(f)

Figure 7: Scatterplots of hourly absolute difference between two tested RG3-M gauges with variation of (a) wind speed and (b) rain intensity, respectively, and (c) three-dimension relationship of the three variables (hourly absolute difference, wind speed, and rain intensity). (d), (e), and (f) correspond to (a), (b), and (c), respectively, but for averaged hourly difference between the RG3-M gauge and the JDZ05 gauge.

splashing out of the gauge especially for larger rainfall intensity.

Our experiments indicate that the RG3-M gauge seems to be suitable for observing the rain intensities at the moderate range of $1.5-3.0 \mathrm{~mm} / \mathrm{h}$. As for the hourly rainfall measurement, the underestimation of the RG3-M gauge seems to be serious with the increasing rain intensity especially for the range beyond $3 \mathrm{~mm} / \mathrm{h}$. By analysing the impact of both wind speed and rainfall intensity on measurements of RG3-M, we found that rainfall intensity has a significant influence on the measuring accuracy of RG3-M, but the wind effect was not detected in our experiments. The missing correlation with wind can be attributed to the similar exposure of the compared gauges in the current experimental setup. To improve the experimental conditions, two sets of raindrop spectrometers and a new windshield device have been tested in our experimental field. In the further research, the systematic mechanical biases of tested TBRs should be completely corrected.

The preliminary evaluation reported here can provide a wider recognition of the RG3-M gauge for the hydrological and meteorological users. However, owing to the limited number of samples and the lack of special wind-proof instalments, the measuring characteristics of RG3-M, such as seasonality, climatic applicability, and wind impacts, are not completely revealed in this study. In the future, efforts will be focused on investigating these physical features of the RG3$M$ gauge under different meteorological conditions with a longer observation period and more experimental data.

\section{Data Availability}

The data used to support the findings of this study are available from the corresponding author upon request.

\section{Conflicts of Interest}

The authors declare that there are no conflicts of interest regarding the publication of this paper.

\section{Acknowledgments}

This work would not have been possible without the cooperation of the observers at the Chuzhou hydrological experiment station. The authors would like to acknowledgment Nanjing Hydraulic Research Institute for providing data and feedback on various aspects of data collection and quality and gauge maintenance. This work was financially supported by National Key Research and Development Program of China (2018YFA060202) and the National Natural Science Foundation of China (51979073, 91647203, 51609145).

\section{Supplementary Materials}

Figure: comparison of screen strainer and mesh size between RG3-M and the manual gauge. Note that the screen mesh of RG3-M usually forms a thin liquid film during rainfall which easily makes raindrops rebounding out of the strainer. Thus, 
more raindrops splash out of the RG3-M gauge than those of manual gauge, especially for the storm with high intensity. (Supplementary Materials)

\section{References}

[1] M. R. Allen and W. J. Ingram, "Constraints on future changes in climate and the hydrologic cycle," Nature, vol. 419, no. 6903, pp. 224-232, 2002.

[2] B. Yong, D. Liu, J. J. Gourley et al., "Global view of real-time TRMM multisatellite precipitation analysis: implications for its successor global precipitation measurement mission," Bulletin of the American Meteorological Society, vol. 96, no. 2, pp. 283-296, 2015.

[3] C. E. Duchon and G. R. Essenberg, "Comparative rainfall observations from pit and aboveground rain gauges with and without wind shields," Water Resource Research, vol. 37, no. 12, pp. 3253-3263, 2001.

[4] D. Yang, B. Goodison, J. Metcalfe et al., "Compatibility evaluation of national precipitation gage measurements," Journal of Geophysical Research: Atmospheres, vol. 106, no. D2, pp. 1481-1491, 2001.

[5] D. Yang and A. Simonenko, "Comparison of winter precipitation measurements by six Tretyakov gauges at the Valdai experimental site," Atmosphere-Ocean, vol. 52, no. 1, pp. 39-53, 2014.

[6] V. S. Golubev, P. Y. Groisman, and R. G. Quayle, "An evaluation of the United States standard 8-in nonrecording raingage at the Valdai Polygon, Russia," Journal of Atmospheric and Oceanic Technology, vol. 9, no. 5, pp. 624-629, 1992.

[7] E. J. Sadler and W. J. Busscher, "High-intensity rainfall rate determination from tipping-bucket rain gauge data," Agronomy Journal, vol. 81, no. 6, pp. 930-934, 1989.

[8] D. Yang, D. L. Kane, L. D. Hinzman et al., "An evaluation of the Wyoming gauge system for snowfall measurement," Water Resources Research, vol. 36, no. 9, pp. 2665-2677, 2000.

[9] D. Yang, "Double fence intercomparison reference (DFIR) vs. Bush gauge for "true" snowfall measurement," Journal of Hydrology, vol. 509, pp. 94-100, 2014.

[10] D. Yang, B. E. Goodison, J. R. Metcalfe et al., "Accuracy of NWS 8" standard nonrecording precipitation gauge: results and application of WMO intercomparison," Journal of Atmospheric and Oceanic Technology, vol. 15, no. 1, pp. 54-68, 1998.

[11] L. G. Lanza and E. Vuerich, "The WMO field intercomparison of rain intensity gauges," Atmospheric Research, vol. 94, no. 4, pp. 534-543, 2009.

[12] L. G. Lanza and L. Stagi, "High resolution performance of catching type rain gauges from the laboratory phase of the WMO field intercomparison of rain intensity gauges," Atmospheric Research, vol. 94, no. 4, pp. 555-563, 2009.

[13] M. Colli, L. G. Lanza, and P. La Barbera, "Performance of a weighing rain gauge under laboratory simulated time-varying reference rainfall rates," Atmospheric Research, vol. 131, pp. 3-12, 2013.

[14] M. Stagnaro, M. Colli, L. G. Lanza, and P. W. Chan, "Performance of post-processing algorithms for rainfall intensity using measurements from tipping-bucket rain gauges," Atmospheric Measurement Techniques, vol. 9, no. 12, pp. 56995706, 2016.

[15] V. S. Shedekar, K. W. King, N. R. Fausey, A. B. O. Soboyejo, R. D. Harmel, and L. C. Brown, "Assessment of measurement errors and dynamic calibration methods for three different tipping bucket rain gauges," Atmospheric Research, vol. 178179, pp. 445-458, 2016.

[16] L. G. Lanza, E. Vuerich, and I. Gnecco, "Analysis of highly accurate rain intensity measurements from a field test site," Advances in Geosciences, vol. 25, pp. 37-44, 2010.

[17] A. Tokay, D. B. Wolff, K. R. Wolff, and P. Bashor, "Rain gauge and disdrometer measurements during the keys area microphysics project (KAMP)," Journal of Atmospheric and Oceanic Technology, vol. 20, no. 11, pp. 1460-1477, 2003.

[18] I. Y. Sulen and J. Reuder, "Predictability of precipitation in complex terrain - a comparison of high-resolution rain gauge measurements and fine-scale numerical simulations," in Proceedings of the EGU General Assembly 2009, Vinenna, Austria, April 2009.

[19] O. S. Vallejosbarra, R. M. Pizarrotapia, M. A. V. Sandoval et al., "Effect of vegetation on precipitation interception in the Andean foothills of the Maule region, Chile," Biological Trace Element Research, vol. 135, no. 1-3, p. 182, 2010.

[20] R. Zhao, J. Zhang, L. I. Yuting et al., "Soil moisture characteristics and its response to rainfall in artificial forests in Loess region of Western Shanxi province," Journal of Soil and Water Conservation, vol. 30, no. 1, pp. 178-183, 2016, in Chinese.

[21] J. C. Rodda and H. Dixon, "Rainfall measurement revisited," Weather, vol. 67, no. 5, pp. 131-136, 2012.

[22] The First Editorial Room of Standards Press of China, Compilation of National Standards for Hydrological Instruments, Standards Press of China, Beijing, China, 2010.

[23] X. Li, J. Liu, A. Liao et al., "Evaluation of measurement errors for eight domestic tipping bucket rain gauges," Water Resources and Power, vol. 37, no. 6, pp. 160-163, 2019, in Chinese.

[24] A. Tokay, P. G. Bashor, and V. L. McDowell, "Comparison of rain gauge measurements in the Mid-Atlantic region," Journal of Hydrometeorology, vol. 11, no. 2, pp. 553-565, 2010.

[25] V. S. Shedekar, L. C. Brown, M. Heckel et al., "Measurement errors in tipping bucket rain gauges under different rainfall intensities and their implication to hydrologic models," in Proceedings of the 2009 ASABE Annual International Meeting, Reno, Nevada, USA, June 2009.

[26] A. Molini, L. G. Lanza, and P. L. Barbera, "The impact of tipping-bucket raingauge measurement errors on design rainfall for urban-scale applications," Hydrological Processes, vol. 19, no. 5, pp. 1073-1088, 2005.

[27] D. Yang, B. E. Goodison, J. R. Metcalfe et al., "Quantification of precipitation measurement discontinuity induced by wind shields on national gauges," Water Resources Research, vol. 35, no. 2, pp. 491-508, 1999.

[28] M. D. Pollock, G. O’Donnell, P. Quinn et al., "Quantifying and mitigating wind-induced undercatch in rainfall measurements," Water Resources Research, vol. 54, no. 6, pp. 38633875, 2018.

[29] M. Colli, R. Rasmussen, J. M. Thériault, L. G. Lanza, C. B. Baker, and J. Kochendorfer, "An improved trajectory model to evaluate the collection performance of snow gauges," Journal of Applied Meteorology and Climatology, vol. 54, no. 8, pp. 1826-1836, 2015.

[30] V. Nešpor and B. Sevruk, "Estimation of wind-induced error of rainfall gauge measurements using a numerical simulation," Journal of Atmospheric and Oceanic Technology, vol. 16, no. 4, pp. 450-464, 1999. 

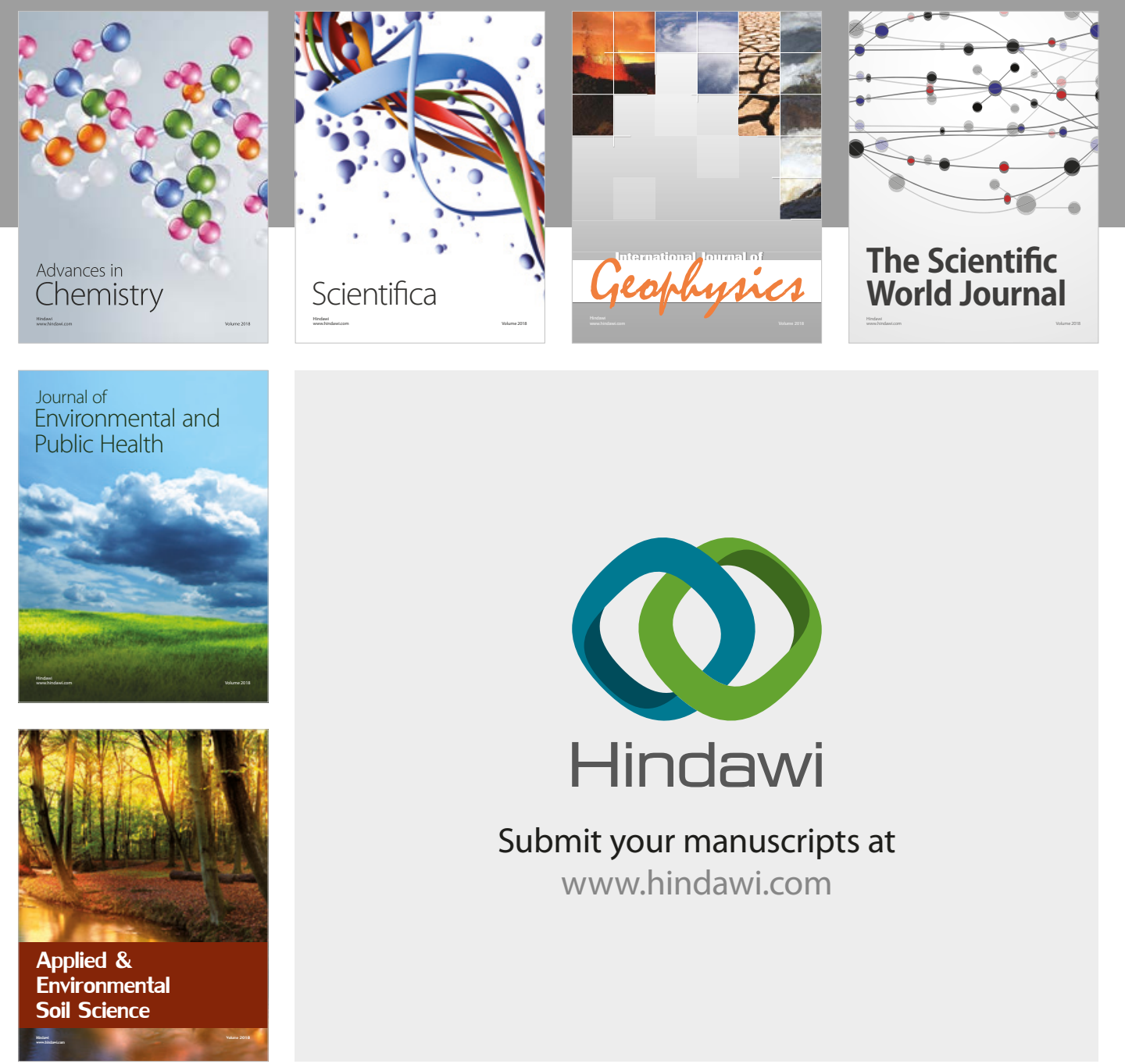

The Scientific

\section{World Journal}
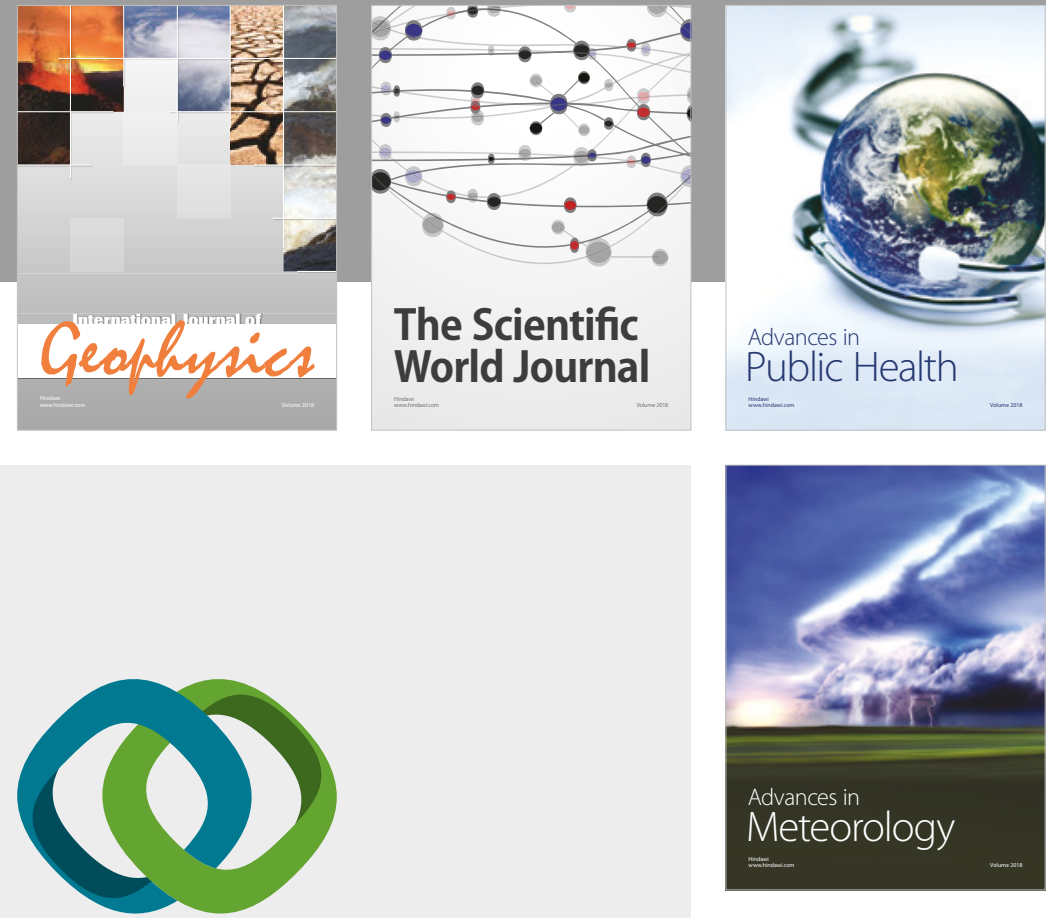

Advan

Public Health

\section{Hindawi}

Submit your manuscripts at

www.hindawi.com
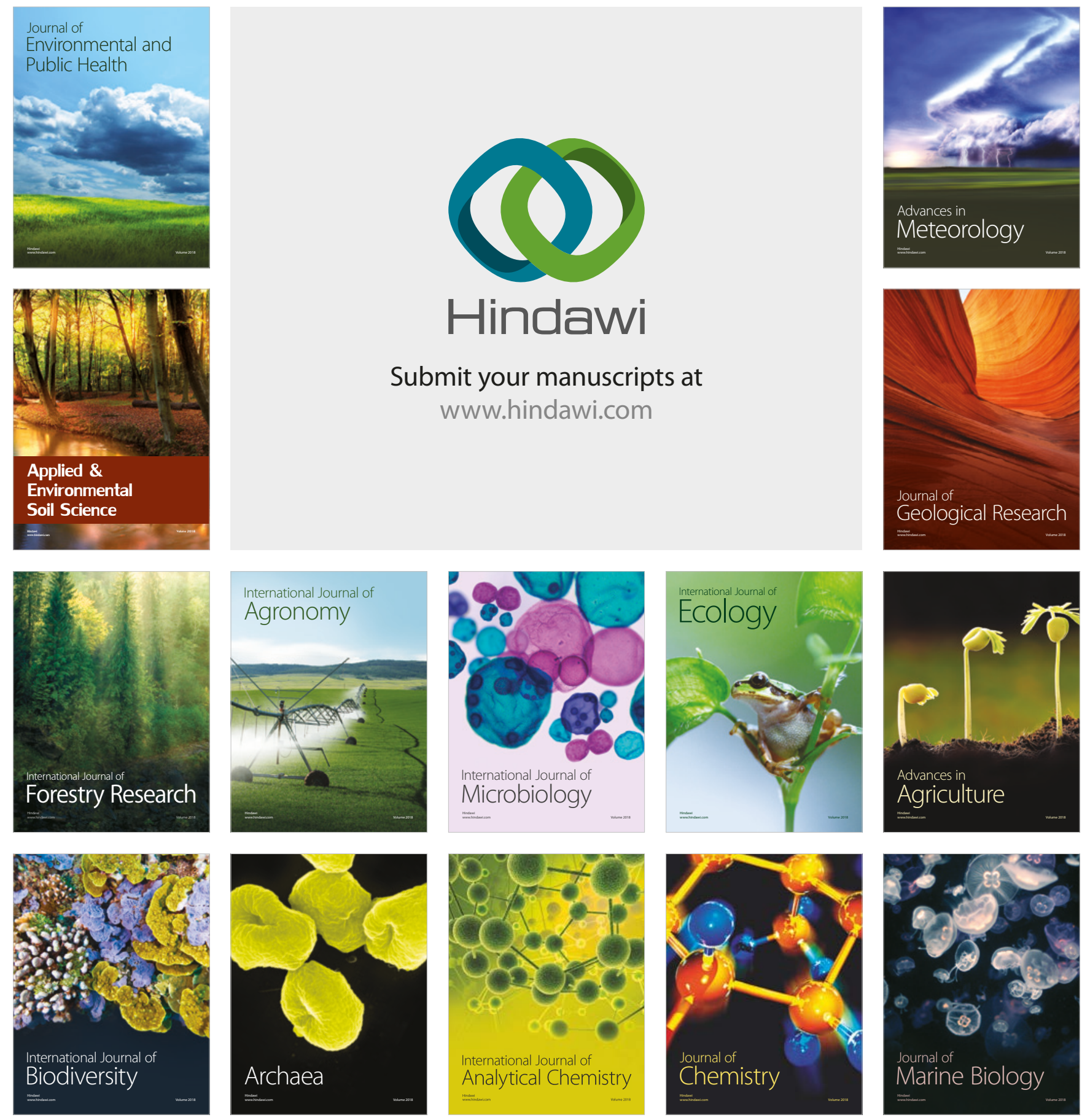